\title{
Peripapillary retinal nerve fiber layer and foveal thickness in hypermetropic anisometropic amblyopia
}

This article was published in the following Dove Press journal:

Clinical Ophthalmology

12 April 2014

Number of times this article has been viewed

\section{Elvan Yalcin' \\ Ozlem Balci² \\ 'World Eye Hospital, Department of Pediatric Ophthalmology, ${ }^{2}$ Kolan Hospitalium Group, Istanbul, Turkey}

Correspondence: Elvan Yalcin Alemdağ S Aquamanors 43 -A Y, Dudullu İstanbul 34000, Istanbul, Turkey Tel +90532 2625719

Fax +90216 6444083

Email elvanyaln@hotmail.com
Purpose: To evaluate whether there was a difference in peripapillary retinal nerve fiber layer (RNFL) and foveal thickness between amblyopic and normal individuals with optical coherence tomography.

Materials and methods: Sixty patients, 30 patients with hypermetropic anisometropic amblyopia and 30 normal emmetropic subjects, were enrolled in this study. The eyes of the participants were divided into three groups: 30 eyes of 30 patients with amblyopia (A), 30 fellow eyes of the amblyopic patients (B), and 30 eyes of 30 normal subjects (C). Emmetropic normal subjects included cases with normal visual acuity and unremarkable ocular examinations. After routine ophthalmic examination, peripapillary retinal nerve fiber layer and foveal thickness measurements were measured by time-domain optical coherence tomography and compared among the three groups.

Results: The difference in RNFL thickness between amblyopic eyes, fellow eyes of the amblyopic patients, and normal eyes of the emmetropic subjects was not clinically significant. However, the mean foveal thickness was significantly thicker in amblyopic eyes versus the fellow eyes and normal subjects' eyes.

Conclusion: Our results suggest that amblyopia seems to have an effect on the foveal thickness, but not on the RNFL thickness.

Keywords: RNFL thickness, foveal thickness, amplyopia

\section{Introduction}

Amblyopia is the most frequent cause of reduced vision (unilateral or bilateral) in children; demonstrated by deficiencies such as loss of Snellen and grating acuity, ${ }^{1,2}$ loss of contrast sensitivity, ${ }^{3}$ and creation of distortions in the perceived shape of a stimulus. ${ }^{4}$ It has been estimated to affect $1 \%-5 \%$ of the population. ${ }^{5}$ Amblyopia frequently occurs during the first 2-3 years of childhood. However, it may also occur in children up to 8-9 years of age. ${ }^{6}$ Amblyopia can be associated with strabismus, anisometropia, or disruption of normal development of the lateral geniculate body during the neonatal period. ${ }^{7-12}$ However, the initial neural site corresponding to this visual deficit observed in this condition is still under investigation. The loss of vision is thought to be secondary to abnormal relationships of the neuronal network within the primary visual cortex. Nevertheless, it has been hypothesized that amblyopia may affect the postnatal maturation of the retina, including the postnatal reduction of retinal ganglion cells, which could lead to a measurable increase in retinal nerve fiber layer (RNFL) thickness. Interestingly enough, where some studies have found increased RNFL thickness in amblyopic eyes, others have not. ${ }^{13-15}$ Red-free ophthalmoscopy, scanning 
laser polarimetry, and optical coherence tomography (OCT) can evaluate retinal nerve fiber layer thickness. OCT is a noninvasive, noncontact technique that visualizes the retina and has increasingly been used in ophthalmology.

This study attempted to evaluate whether there was a difference in foveal and peripapillary RNFL thickness between amblyopic and normal individuals with optical coherence tomography.

\section{Materials and methods}

This prospective, cross-sectional study enrolled 60 patients with ages ranging from 8 to 14 years. The study was approved by the World Eye Hospital institutional medical ethics committee and was conducted in accordance with the Declaration of Helsinki. Written informed consent was also obtained from each individual's parents. The study included 30 unilateral hypermetropic anisometropic amblyopic patients and 30 emmetropic normal subjects. Hypermetropic anisometropic amblyopic patients included outpatients who met the following inclusion criteria; amblyopic patients with no history of intraocular surgery, neurological disease, retinal disease, glaucoma, nystagmus, or strabismus. An amblyopic eye was defined as an eye that has a visual acuity of at least two lines worse than the normal eye using the Snellen chart. Anisometropia was defined as a cycloplegic spherical equivalent difference greater than 2.00 diopter (D) between fellow eyes. Emmetropic normal subjects included cases with normal visual acuity and unremarkable ocular examinations. The right eye of each normal subject was evaluated. The eyes of the participants were divided into three groups: 30 eyes of 30 patients with amblyopia (A), 30 fellow eyes of the amblyopic patients (B), and 30 eyes of 30 normal subjects (C). All patients were evaluated by a detailed eye examination, which included manifest refraction, best corrected visual acuity using a Snellen chart, cycloplegic refraction using cyclopentolate hydrochloride $1 \%$, coveruncover test, prism test, extraocular movements, intraocular pressure measurement, slit-lamp biomicroscopy, and dilated fundus examination. Intraocular pressure, anterior segment, and fundus examination were normal in all eyes. The foveal and peripapillary RNFL thicknesses were measured by timedomain OCT (OCT 3000, version A 3.0; Carl Zeiss, Inc, Dublin, CA, USA). OCT scans were performed when pupils were dilated. Signal strength was rated on a 10-point scale: signal strength values of $>6$ were considered acceptable. All our patients had the ability to maintain steady fixation at the OCT, and each scan was accurately checked to avoid misalignment of imaging.
Each OCT was performed by the same technician. Two protocols were performed for each eye of every subject in the following order: the fast macular thickness scan map and the fast RNFL thickness scan map. The fast macular thickness map consists of six radial scans centered on the fovea, with each scan formed by 128 single A scans. The machine displays the thickness values in three rings. The foveal area corresponds to the innermost $1 \mathrm{~mm}$ diameter, the inner ring to $3 \mathrm{~mm}$ diameter, and the outer ring to $6 \mathrm{~mm}$ diameter. The foveal thickness corresponds to the mean thickness in the central 1,000 microns diameter area. The fast RNFL thickness scan (3.4 mm circle protocol) consists of 256 individual A scans in a path around the circumference of a circle 3.46 $\mathrm{mm}$ in diameter and centered around the optic nerve. The machine scans the area three times consecutively, and gives the average thickness value of the three scans. Internal fixation was used for macular scanning, and external fixation for optic disc scanning.

The statistical analyses were done using SPSS 15.0 (Statistical Package for Social Sciences; IBM Corporation, Armonk, NY, USA) software package. Descriptive statistical methods (mean, standard deviation) were used for data evaluation. A one-way analysis of variance test followed by a post hoc Bonferroni correction was used for comparing the groups. A $P$-value of less than 0.05 was considered statistically significant.

\section{Results}

The study included 30 ( $\mathrm{n}=30$ eyes) hypermetropic anisometropic amblyopic patients and 30 ( $n=30$ eyes) normal emmetropic subjects. The amblyopic patients included 15 females and 15 males, the mean age was 10.5 years (range 8 to 14 years). Mean spherical equivalent of cycloplegic refraction was $+4.75 \mathrm{D}$ (range +3.00 to $+6.00 \mathrm{D})$ in the amblyopic eyes. The mean spherical eguivalent of the cycloplegic refraction was $+1.00 \mathrm{D}$ (range $+0.50 \mathrm{D}$ to $+2.00 \mathrm{D}$ ) in the fellow eyes. Mean best corrected visual acuity was 0.42 (range 0.2 to 0.8 ) in amblyopic eyes and 1.0 in the fellow eyes. Emmetropic subjects included 15 females and 15 males, the mean age was 10.2 years (range 8 to 14 years).

The mean RNFL thickness for Group A was $101 \pm 10.77$ microns; for Group B, it was $104.4 \pm 10.95$ microns, and for Group C, $105.08 \pm 10.10$ microns. One-way analysis of variance test revealed no statistically significant difference between these three groups $(P=0.285)$. The mean foveal thickness for Group A was 220 \pm 38.25 microns; for Group B, it was 202.87 \pm 31.01 microns, and for Group C, 198.91 \pm 22.50 microns. We found a statistical difference between groups 
$(P=0.025)$. The difference between Group A and Group B was statistically significant $(P=0.038)$. There was also a significant statistical difference in macular thickness between Group A and Group C $(P=0.028)$. The difference between Group B and Group $C$ was not statistically significant $(P=0.06)$.

\section{Discussion}

Amblyopia may have different effects at various levels of the visual pathway. Receiving input from the amblyopic eye causing atrophy for the cells in the lateral geniculate nucleus has been reported. ${ }^{10-12}$ Several experiments have demonstrated that light deprivation can cause modifications of retinal ganglion cells, such as cell loss, ${ }^{2}$ mean nuclear volume diminution in ganglion cell cytoplasm, internal plexiform layer thinning in rats and cats, ${ }^{3}$ and reduction in optic nerve size area in mice. ${ }^{16}$ In many studies, retinal changes were investigated using imaging devices. Several OCT studies have investigated the RNFL in amblyopia. OCT studies of RNFL thickness in amblyopia reported different findings. Colen et $\mathrm{l}^{13}$ measured RNFL thickness in strabismus amblyopia and reported no significant difference between amblyopic and fellow eyes. Bozkurt et al, ${ }^{14}$ using a third-generation retinal nerve fiber analyzer, reported no significant difference in the RNFL thickness in amblyopic and fellow eyes. Altintas et al ${ }^{17}$ reported that the RNFL thickness was thicker in amblyopic eyes, but that the difference was not statistically significant. Kee et al ${ }^{18}$ reported that there was no statistically significant difference in the RNFL thickness between amblyopic and normal fellow eyes. Repka et al ${ }^{19}$ measured the thickness of the peripapillary RNFL in amblyopic and fellow eyes. They found no significant difference in the RNFL thickness. Firat et $\mathrm{al}^{20}$ found no significant difference between amblyopic and normal eyes. In contrast to these studies, Yen et al ${ }^{15}$ measured RNFL thickness in patients with unilateral amblyopia (strabismic and refractive amblyopia) and found no significant difference between strabismic amblyopic and normal eyes, although the RNFL was thicker in eyes with refractive amblyopia. Similarly, Yoon et al ${ }^{21}$ measured the macular and peripapillary RNFL in patients with anisometropic amblyopia. They reported that the RNFL in patients with amblyopia was significantly thicker. In this study, our results are similar with those reported by Colen et al, ${ }^{13}$ Bozkurt et al, ${ }^{14}$ Altintas et al, ${ }^{17}$ Kee et al, ${ }^{18}$ Repka et al, ${ }^{19}$ and Firat et al, ${ }^{20}$ but are different from the results reported by Yen et al ${ }^{15}$ and Yoon et al. ${ }^{21}$

Macular nerve fiber layer is another parameter that has been investigated by several studies. Kee et al ${ }^{18}$ reported that there were no statistically significant differences in the fovea thickness between normal and amblyopic children.
Yoon et $\mathrm{al}^{21}$ reported that there was no significant difference in macular thickness. They concluded that RNFL in patients with amblyopia was significantly thicker; the amblyopic process may involve the peripapillary RNFL, but not the macula. Firat et $\mathrm{al}^{20}$ measured the macular, superior, and inferior ganglion cell complex thickness in amblyopic, fellow, and control eyes by spectral domain OCT. There was no statistically significant difference among the amblyopic, fellow, and control eyes in the thickness of these three parameters. Huynh et $\mathrm{al}^{22}$ measured slightly thicker foveal thickness in amblyopic eyes with spectral-domain OCT, although the difference was not statistically significant. Another spectral-domain OCT study demonstrated that the mean macular thickness was significantly increased in amblyopic eyes versus the fellow eye, while the mean RNFL thickness was similar. ${ }^{24}$ Similar to Huynh et $\mathrm{al}^{22}$ and $\mathrm{Al} \mathrm{Haddad}{ }^{23}$ et al, we found that foveal thickness is increased in amblyopic eyes of the amblyopia patients. This difference was also clinically significant.

OCT has become a widely used tool in clinical ophthalmology. Normative data are provided automatically by OCT, but the database only includes individuals 18 years and older, limiting its use in children. There are several reports regarding the difference in the RNFL thickness between children and adults. ${ }^{24-36}$ Possible explanations of difference from various studies include race, age, axial length, and disc area. The differences between different versions of the device have also been found in adults, and may be due to the use of different algorithms between spectral and time domain OCT devices; $;^{37-40}$ making a comparison between different devices can be misleading. Similarly, several studies on the variations of macular thickness measurements in normal subjects according to age and refractive error/axial length have been reported. Some studies ${ }^{41-43}$ have shown reductions in macular thickness with age, whereas others ${ }^{44}{ }^{48}$ have found no significant correlation. More recent studies in which the third-generation Stratus OCT was used have shown average macular thickness ${ }^{49}$ and macular volume ${ }^{50}$ to be related to refractive error/axial length in normal subjects, as in histopathologic studies. ${ }^{51}$

\section{Conclusion}

In this study, the foveal and peripapillary RNFL thicknesses were measured by time-domain OCT. The results showed that the foveal thickness was significantly thicker in amblyopic eyes, although the peripapillary RNFL was not significantly different between amblyopic eyes, fellow eyes, and normal eyes.

The main limitations of this study were not assessing the relationships between RNFL, macular thickness, and age/ 
refractive errors. Because the ranges of age and refractive errors of the amblyopic patients and normal individuals are similar to each other, we did not investigate the relationship between these parameters and only measured the mean RNFL and foveal thickness. Also, this study included a small sample size.

In conclusion, our results suggest that amblyopia seems to have a significant effect on the foveal thickness, but not on the RNFL thickness. Further studies, including histopathological and instrumental studies with a greater number of patients, are required to confirm the differences between amblyopic and normal eyes.

\section{Disclosure}

The authors declare no conflicts of interest in this work.

\section{References}

1. Rasch E, Swift H, Riesen AH, Chow KL. Altered structure and composition of retinal cells in darkreared mammals. Exp Cell Res. 1961;25: 348-363.

2. Wendell-Smith CP. Effect of light deprivation on the postnatal development of the optic nerve. Nature. 1964;204:707.

3. Chow KL. Failure to demonstrate changes in the visual system of monkeys kept in darkness or in colored lights. J Comp Neurol. 1955;102(3): 597-606.

4. Chauban S, Marshall J. The interpretation of optical coherence tomography image of the retina. Invest Ophthalmol Vis Sci. 1999;40: 2332-2342.

5. Webber JL, Wood J. Amblyopia: Prevelance, natural history, functional effects and treatment. Clin Exp Optom. 2005;88(6):365-375.

6. Webber AL. Amblyopia treatment: an evidence-based approach to maximising treatment outcome. Clin Exp Optom. 2007;90(4):250-257.

7. Headon MP, Powell TP. Cellular changes in the lateral geniculate nucleus of infant monkeys after suture of the eyelids. J Anat. 1973;116(Pt 1):135-145.

8. Sherman SM, Wilson JR. Behavioral and morphological evidence for binocular competition in the postnatal development of the dog's visual system. J Comp Neurol. 1975;161(2):183-195.

9. von Noorden GK. Histological studies of the visual system in monkeys with experimental amblyopia. Invest Ophthalmol. 1973;12(10): 727-738.

10. Wiesel TN, Hubel DH. Effect of visual deprivation on morphology and physiology of cells in the cat's lateral geniculate body. J Neurophysiol. 1963;26:978-993.

11. von Noorden GK, Crawford MLJ, Levacy RA. The lateral geniculate nucleus in human anisometropic amblyopia. Invest Ophthalmol Vis Sci. 1983;24:788-790.

12. von Noorden GK, Crawford ML. The lateral geniculate nucleus in human strabismic amblyopia. Invest Ophthalmol Vis Sci. 1992;33: 2729-2732.

13. Colen TP, de Faber JT, Lemij HG. Retinal nerve fiber layer thickness in human strabismic amblyopia. Binocul Vis Strabismus Q. 2000;15: $141-146$.

14. Bozkurt B, Irkeç M, Orhan M, Karaağaoğlu E. Thickness of the retinal nerve fiber layer in patients with anisometropic and strabismic amblyopia. Strabismus. 2003;11(1):1-7.

15. Yen MY, Cheng CY, Wang AG. Retinal nerve fiber layer thickness in unilateral amblyopia. Invest Ophthalmol Vis Sci. 2004;45:2224-2230.

16. Russell EL, Kada JM, Hufhines DM. Orange County vision screening project. Ophthalmologic evaluation. Sight Saving Rev. 1961;31: 215-219.
17. Altintas O, Yüksel N, Ozkan B, CaglarY. Thickness of the retinal nerve fiber layer, macular thickness, and macular volume in patients with strabismic amblyopia. J Pediatr Ophthalmol Strabismus. 2005;42(4): 216-221.

18. Kee SY, Lee SY, Lee YC. Thicknesses of the fovea and retinal nerve fiber layer in amblyopic and normal eyes in children. Korean $J$ Ophthalmol. 2006;20(3):177-181.

19. Repka MX, Kraker RT, Tamkins SM, Suh DW, Sala NA, Beck RW; Pediatric Eye Disease Investigator Group. Retinal nerve fiber layer thickness in amblyopic eyes. Am J Ophthalmol. 2009;148(1):143-147.

20. Firat PG, Ozsoy E, Demirel S, Cumurcu T, Gunduz A. Evaluation of peripapillary retinal nerve fiber layer, macula and ganglion cell thickness in amblyopia using spectral optical coherence tomography. Int J Ophthalmol. 2013;6(1):90-94.

21. Yoon SW, Park WH, Baek SH, Kong SM. Thicknesses of macular retinal layer and peripapillary retinal nerve fiber layer in patients with hyperopic anisometropic amblyopia. Korean J Ophthalmol. 2005;19(1): 62-67.

22. Huynh SC, Samarawickrama C, Wang XY, et al. Macular and nerve fiber layer thickness in amblyopia: the Sydney Childhood Eye Study. Ophthalmology. 2009;116(9):1604-1609.

23. Al-Haddad CE, Mollayess GM, Cherfan CG, Jaafar DF, Bashshur ZF. Retinal nerve fibre layer and macular thickness in amblyopia as measured by spectral-domain optical coherence tomography. $\mathrm{Br} J$ Ophthalmol. 2011;95(12):1696-1699.

24. Parikh RS, Parikh SR, Sekhar GC, Prabakaran S, Babu JG, Thomas R. Normal age-related decay of retinal nerve fiber layer thickness. Ophthalmology. 2007;114(5):921-926.

25. Huynh SC, Wang XY, Rochtchina E, Mitchell P. Peripapillary retinal nerve fiber layer thickness in a population of 6-year-old children: findings by optical coherence tomography. Ophthalmology. 2006;113(9):1583-1592.

26. Huynh SC, Wang XY, Rochtchina E, Crowston JG, Mitchell P. Distribution of optic disc parameters measured by OCT: findings from a population-based study of 6-year-old Australian children. Invest Ophthalmol Vis Sci. 2006;47(8):3276-3285.

27. Salchow DJ, Oleynikov YS, Chiang MF, et al. Retinal nerve fiber layer thickness in normal children measured with optical coherence tomography. Ophthalmology. 2006;113:786-791.

28. Ahn HC, Son HW, Kim JS, Lee JH. Quantitative analysis of retinal nerve fiber layer thickness of normal children and adolescents. Korean J Ophthalmol. 2005;19(3):195-200.

29. El-Dairi MA, Asrani SG, Enyedi LB, Freedman SF. Optical coherence tomography in the eyes of normal children. Arch Ophthalmol. 2009;127: $50-58$.

30. Leung MM, Huang RY, Lam AK. Retinal nerve fiber layer thickness in normal Hong Kong chinese children measured with optical coherence tomography. J Glaucoma. 2010;19(2):95-99.

31. Samarawickrama C, Wang JJ, Huynh SC, et al. Ethnic differences in optic nerve head and retinal nerve fibre layer thickness parameters in children. Br J Ophthalmol. 2010;94(7):871-876.

32. Qian J, Wang W, Zhang X, et al. Optical coherence tomography measurements of retinal nerve fiber layer thickness in chinese children and teenagers. J Glaucoma. 2011;20(8):509-513.

33. Gupta G, Donahue JP, You T. Profile of the retina by optical coherence tomography in the pediatric age group. Am J Ophthalmol. 2007;144(2): 309-310.

34. Blumenthal EZ, Williams JM, Weinreb RN, Girkin CA, Berry CC, Zangwill LM. Reproducibility of nerve fiber layer thickness measurements by use of optical coherence tomography. Ophthalmology. 2000;107:2278-2282.

35. Larsson E, Eriksson U, Alm A. Retinal nerve fibre layer thickness in fullterm children assessed with Heidelberg retinal tomography and optical coherence tomography: normal values and interocular asymmetry. Acta Ophthalmol. 2011;89(2):151-158.

36. Turk A, Ceylan OM, Arici C, et al. Evaluation of the nerve fiber layer and macula in the eyes of healthy children using spectral-domain optical coherence tomography. Am J Ophthalmol. 2012;153(3):552-559. e1. 
37. Leung CK, Chiu V, Weinreb RN, et al. Evaluation of retinal nerve fiber layer progression in glaucoma: a comparison between spectral-domain and time-domain optical coherence tomography. Ophthalmology. 2011;118(8):1558-1562.

38. Knight OJ, Chang RT, Feuer WJ, Budenz DL. Comparison of retinal nerve fiber layer measurements using time domain and spectral domain optical coherent tomography. Ophthalmology. 2009;116(7): 1271-1277.

39. Sung KR, Kim DY, Park SB, Kook MS. Comparison of retinal nerve fiber layer thickness measured by Cirrus HD and Stratus optical coherence tomography. Ophthalmology. 2009;116(7):1264-1270.

40. Leite MT, Rao HL, Weinreb RN, et al. Agreement among spectraldomain optical coherence tomography instruments for assessing retinal nerve fiber layer thickness. Am J Ophthalmol. 2011;151(1): 85-92. e1.

41. Kanai K, Abe T, Murayama K, Yoneya S. [Retinal thickness and changes with age]. Nihon Ganka Gakkai Zasshi. 2002;106(3):162-165. Japanese.

42. Eriksson U, Alm A. Macular thickness decreases with age in normal eyes: a study on the macular thickness map protocol in the Stratus OCT. Br J Ophthalmol. 2009;93(11):1448-1452.

43. Manassakorn A, Chaidaroon W, Ausayakhun S, Aupapong S, Wattananikorn S. Normative database of retinal nerve fiber layer and macular retinal thickness in a Thai population. Jpn J Ophthalmol. 2008;52(6):450-456.

44. Zou H, Zhang X, Xu X, Yu S. Quantitative in vivo retinal thickness measurement in chinese healthy subjects with retinal thickness analyzer. Invest Ophthalmol Vis Sci. 2006;47(1):341-347.
45. Chan CM, Yu JH, Chen LJ, et al. Posterior pole retinal thickness measurements by the retinal thickness analyzer in healthy Chinese subjects. Retina. 2006;26(2):176-181.

46. Kremser B, Troger J, Baltaci M, Kralinger M, Kieselbach GF. Retinal thickness analysis in subjects with different refractive conditions. Ophthalmologica. 1999;213(6):376-379.

47. Göbel W, Hartmann F, Haigis W. [Determination of retinal thickness in relation to the age and axial length using optical coherence tomography]. Ophthalmologe. 2001;98(2):157-162. German.

48. Chan A, Duker JS, Ko TH, Fujimoto JG, Schuman JS. Normal macular thickness measurements in healthy eyes using Stratus optical coherence tomography. Arch Ophthalmol. 2006;124(2):193-198.

49. Lam DS, Leung KS, Mohamed S, et al. Regional variations in the relationship between macular thickness measurements and myopia. Invest Ophthalmol Vis Sci. 2007;48(1):376-382.

50. Wu PC, Chen YJ, Chen CH, et al. Assessment of macular retinal thickness and volume in normal eyes and highly myopic eyes with thirdgeneration optical coherence tomography. Eye (Lond). 2008;22(4): 551-555.

51. Apple DJ, Rabb MF. Clinicopathologic Correlation of Ocular Disease: A Text and Stereoscopic Atlas. St Louis: CV Mosby; 1978:39-44.
Clinical Ophthalmology

\section{Publish your work in this journal}

Clinical Ophthalmology is an international, peer-reviewed journal covering all subspecialties within ophthalmology. Key topics include: Optometry; Visual science; Pharmacology and drug therapy in eye diseases; Basic Sciences; Primary and Secondary eye care; Patien Safety and Quality of Care Improvements. This journal is indexed on

Submit your manuscript here: http://www.dovepress.com/clinical-ophthalmology-journal

\section{Dovepress}

PubMed Central and CAS, and is the official journal of The Society of Clinical Ophthalmology (SCO). The manuscript management system is completely online and includes a very quick and fair peer-review system, which is all easy to use. Visit http://www.dovepress.com/ testimonials.php to read real quotes from published authors. 